\title{
CUSTOS E LUCRATIVIDADE NA PRODUÇÃO DE BOVINOS NO SISTEMA DE PECÚARIA EXTENSIVA, NO MUNICÍPIO DE DENISE-MT.
}

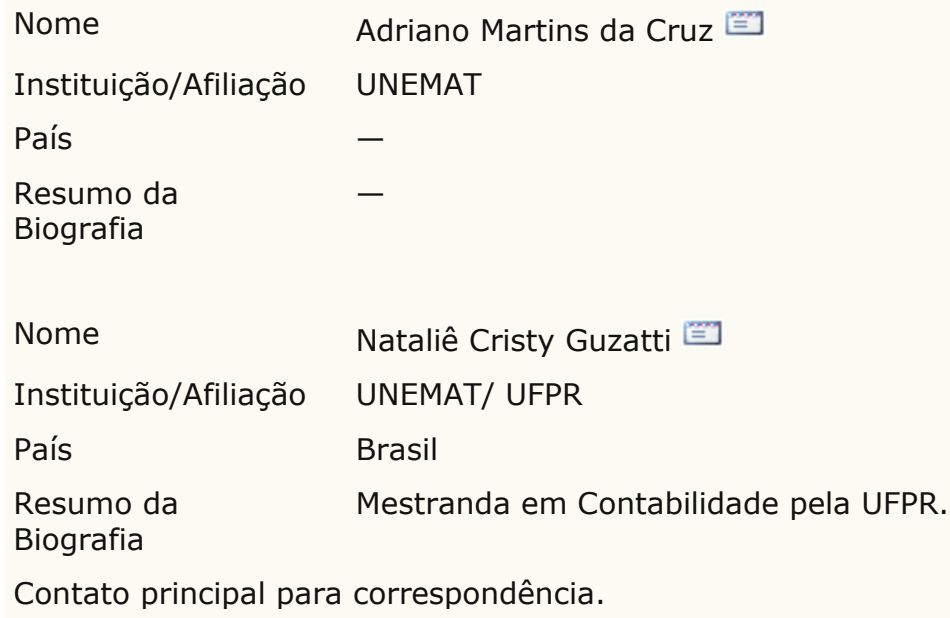

\section{RESUMO}

O presente trabalho teve como objetivo analisar o gerenciamento dos custos incorridos no sistema de produção de gado de corte em pastagem na Fazenda Catarinense no município de Denise - MT, evidenciando a cadeia produtiva da produção, na etapa da engorda no ano de 2015. A metodologia utilizada para o estudo foi de natureza descritiva, com abordagem qualitativo-quantitativa, utilizando como procedimento técnico o estudo de um caso. Os resultados obtidos na pesquisa mostraram a variação de custos e despesas geradas através da produção de bovinos de corte em pastagens, e sua lucratividade ao final do período. Evidenciou-se, através da pesquisa, que a criação de gado para o abate na Fazenda Catarinense é rentável, proporcionando um lucro de aproximadamente 50\% dos custos incorridos na etapa da engorda.

Palavras-chave: Bovinocultura. Custos. Produção.

\section{INTRODUÇÃO}

Atualmente, o cultivo do gado de corte, é uma das atividades mais presentes no setor do agronegócio brasileiro, também conhecida como processo de bovinocultura. Essa pratica está relacionada diretamente com a produção de bezerros, seja eles destinados ao setor de corte, ou produção e reposição do rebanho, pois são nestes setores onde se nota a maior lucratividade do processo. A pecuária de corte tem se destacado principalmente no setor de produção animal, assumindo liderança no mercado mundial de carnes. Hoje o Brasil é portador do maior rebanho comercial do mundo, também ficando em segundo 
lugar como maior produtor de gado bovino do mundo (Empresa Brasileira de Pesquisa e Agropecuária - EMBRAPA, 2014).

A Associação Brasileira das Indústrias Exportadoras de Carne - ABIEC (2013), relata que a bovinocultura de corte representa o maior percentual do setor de agronegócio brasileiro, proporcionando um faturamento de mais de $\mathrm{R} \$ 50$ bilhões de reais por ano, e disponibilizando aproximadamente 7,5 milhões de empregos em todo o território nacional. Para atender as necessidades de demanda da população por produtos cárneos, foram estipuladas metas que desenvolvem práticas nas quais reduzem o número de animais em recria e o tempo de duração da respectiva fase, sendo de suma importância para o crescimento e desenvolvimento do processo produtivo. Assim, este processo intensifica a produção de bovinos e acelera o processo de abate precoce dos mesmos.

Segundo o Ministério de Agricultura, Pecuária e Abastecimento - MAPA (2015), o processo de bovinocultura, é atualmente, uma das principais atividades comerciais do agronegócio nacional, representando o segundo maior rebanho mundial, contendo mais de 200 milhões de cabeças de bovinos em todo o país.

O Estado de Mato Grosso é reconhecido como um dos principais estados brasileiros no cultivo de bovinos de corte. Com o grande número de consumo de carne bovina, seja em território nacional ou internacional, cabe aos produtores, desenvolver e intensificar cada vez mais o processo de criação e reprodução de bovinos de corte em pastagens (Instituto Brasileiro de Geografia e Estatística - IBGE, 2011).

De acordo com uma pesquisa realizada pelo IBGE (2011) o estado do Mato Grosso é o maior produtor de pastagens para bovinos do país, coincidindo diretamente pelo grande sucesso na criação de bovinos em pastagens. Assim o estado apresenta números significativos no número de cabeça de gado produzida em território nacional, apresentando no mesmo ano da pesquisa, 28.651.256 cabeças de gado, atingindo em primeiro lugar o ranking brasileiro.

Para serem atingidos os principais objetivos dos produtores de gado de corte, é necessário que todo o processo esteja ligado diretamente a uma referência em qualidade e produção em grande escala, sendo necessário desenvolver técnicas especificas que auxiliam no processo de bovinocultura, sendo estas, desde o princípio da cria até a produção e reprodução dos mesmos (Associação dos Criadores de Mato Grosso ACRIMAT, 2012). 


\section{Revista

Com base nos investimentos feitos pelos pecuaristas, é necessário ter controle sobre os custos, ter planejamento de venda, saber negociar todos e quaisquer insumos e minerais indispensáveis para seu rebanho, controles como este são de suma importância, pois permite que o pecuarista tenha visão se terá lucratividade, se será necessário reduzir custos ou antecipar as vendas (MEIZ, 2013).

Diante do exposto surgiu a seguinte problemática obteve-se lucratividade na produção de bovinos no ano de 2015 na propriedade rural em análise?

O trabalho justifica-se pela necessidade da empresa em analise adotar uma metodologia comparativa ao diferenciar os custos de produção e lucratividade em termos de comercialização.

Assim, esse artigo tem como objetivo determinar comparativamente os custos de produção e lucratividade na produção de bovino para corte, no sistema de criação extensivo, no ano de 2015 através de levantamento quantitativo e de estudo de caso, verificando deste modo as disparidades.

O presente trabalho oferece uma contribuição ao estudo de caso de custo de produção, tendo como objetivos específicos: a) levantar dados sobre os gastos incorridos na fazenda no período em estudo para desenvolver a atividade pecuária;

b) analisar a lucratividade baseada em custos de produção e preços de comercialização praticada na região identificada.

\section{AGRONEGÓCIO E SEUS CUSTOS}

\subsection{Evolução da Agropecuária no Brasil}

O início da pecuária brasileira confunde-se com a colonização. Era, inicialmente, atividade de subsistência. A distribuição da pecuária para o interior do país seguiu os caminhos da cultura canavieira, se deslocando do litoral em direção às minas gerais, à região centro-oeste e para os sertões nordestinos, enfatiza Costa (2006). Não se imaginava, na época, que cinco séculos mais tarde que se transformaria num dos pilares econômicos do Brasil.

A Confederação Nacional da Agricultura - CNA (2006) afirma que o Brasil é tido como celeiro mundial em termos de agronegócio. O país possui $22 \%$ das terras agricultáveis do mundo, conta com clima diversificado, chuvas regulares, energia solar 


\section{Revista \\ UNEMAT de \\ Contabilidade}

v. 8, n. 16,2019

abundante e quase $13 \%$ de toda a água doce do planeta, além de elevada tecnologia utilizada no campo, dados estes que fazem do agronegócio brasileiro um setor moderno, eficiente e competitivo no cenário internacional.

Segundo pesquisas de Contini et al (2006) agronegócio deve ser entendido como a cadeia produtiva que envolve desde a fabricação de insumos, passando pela produção nos estabelecimentos agropecuários e pela transformação, até seu consumo, Brasil é um grande produtor, consumidor e exportador de carnes. Em relação à carne bovina, é também o segundo maior produtor mundial e seu consumo é o terceiro maior do mundo em 2006. Sua liderança ocorre, também, nas exportações, ocupando, a partir de 2004, o primeiro lugar, com $26,4 \%$ das exportações mundiais de carne bovina.

Nesse sentido, Valle (2007) ajunta que a bovinocultura de corte tem se destacado na economia nacional e vem assumindo posição de liderança no mercado mundial de carnes. O Brasil possui hoje o maior rebanho comercial do mundo; é o segundo maior produtor mundial de carne bovina, com cerca de oito milhões de toneladas, e a partir de 2003 passou a ser o primeiro exportador mundial, com destaque tanto no comércio de carnes frescas como no de industrializadas, reforça ele.

Os indicadores econômicos posicionam os números da produção agropecuária como pilar da sustentação econômica brasileira. De fato, o desempenho da atividade rural no Brasil alcança marcas invejáveis, avalia João Martins da Silva Junior, Presidente da Confederação da Agricultura e Pecuária do Brasil (CNA). Marcas que colocam o País entre os principais produtores de alimentos do mundo, com produtividade, frequentemente, superior ao de países desenvolvidos.

O Brasil deve sofrer uma queda no PIB da ordem de 3\% em 2015 e 1,5\% em 2016. Além dos problemas econômicos e políticos que o país atravessa, a queda nos preços internacionais de commodities tem prejudicado o desempenho dos países exportadores destes produtos, afirma a cartilha Balanço 2015 perspectivas 2016 da CNA.

A CNA (2015) esclarece, ainda, que ao contrário do Produto Interno Bruto do Brasil, o PIB da agropecuária (dentro da porteira) deverá crescer em 2015. De acordo com estimativas, o país sofrerá queda de 3\% em 2015. Já a agropecuária deverá crescer 2,4\%. Este resultado irá ampliar a participação do agronegócio no PIB Brasil para aproximadamente $23 \%$. 


\section{Contabilidade}

\subsubsection{Pecuária de Corte no Mato Grosso}

A pecuária de corte do Brasil e, muito especialmente, a de Mato Grosso, está vivenciando um momento de grandes transformações e de oportunidades para os diversos agentes e detentores dos fatores de produção que fazem de Mato Grosso o Estado que, além de maior produtor do Brasil, produz carne bovina de qualidade, analisam Filho, Giordano e Maciel (2012) em estudos realizados pela Associação dos Criadores de Mato Grosso - ACRIMAT (2012).

O Estado de Mato Grosso é detentor de grandes extensões de terra, cujas características tornam-no propício para o sistema de criação de bovinos em pasto de maneira extensiva. Essa característica coloca-o em posição de destaque frente ao número efetivo do rebanho bovino (HOFFMANN et al, 2014). O estado de Mato Grosso possui 28.651.256 cabeças, colocando-o em primeiro lugar no ranking brasileiro (IBGE, 2011).

Bonjour et al (2008) reforça que, no Mato Grosso, a pecuária extensiva bovina desenvolveu um processo de apropriação e legitimação do uso da terra destinada à agropecuária. O núcleo pioneiro foi o Pantanal, onde houve integração dos bovinos no ecossistema sem impacto grave no bioma.

Na porção centro-oeste do estado do Mato Grosso, destaca-se grande produção de bovinos, sendo constituída pelos municípios de Alto Paraguai, Arenápolis, Barra do Bugres, Campo Novo do Parecis, Denise, Diamantino, Nortelândia, Nova Marilândia, Nova Olímpia, Porto Estrela, Santo Afonso e Tangará da Serra. A região conta com 1.337.723 milhões de cabeças de gado destinados à produção de corte e produção leiteira. (INDEA, 2015).

Entretanto, é preciso entender o processo da formação das pastagens do cerrado para embasar o conhecimento referente à utilização do solo como pastagem para a pecuária, cujo processo pode ser descrito com a derrubada de vegetação para o uso como pasto, sendo a carne, oriunda do abate das reses, destinada ao abastecimento da população, bem como o couro utilizado na fabricação de material de transporte, como bruacas, alforjes e silos, explica Bonjour et al (2008).

Mendes et al (2010) salienta que os produtores de gado de corte, procuram de forma sustentável e menos onerosa, envolver elementos abióticos e bióticos no sistema de produção, tal como ambiente, clima, o solo, sementes das pastagens, e a própria espécie 


\section{Revista

bovina, a escolha da terra por parte do produtor para o cultivo das pastagens tem relação direta com o resultado do processo. Uma terra que apresente solo em boas qualidades apresentará menor onerosidade por parte do produtor.

Devido à grande extensão territorial disponível e às características agropecuárias, o sistema de produção predominante é o de criação extensiva. Neste tipo de criação, o gado é engordado preferencialmente por pastagens e algum complemento alimentar caso seja necessário (MENDES; ZOCCOLOTTO; NOSSA, 2010).

$\mathrm{Na}$ busca de maior eficiência, os produtores passaram a utilizar processos produtivos mais modernos. Como tal, o confinamento e o uso de biomassa, estão sendo introduzidos em algumas regiões do estado de Mato Grosso, afirma Bonjour et al (2008).

\subsubsection{Ciclo de Produção de Bovinos de Corte}

O processo de criação de bovinos está dividido basicamente em três fases: cria, recria e engorda, conforme figura a seguir:

Figura 01 - Fases do ciclo de criação de bovinos

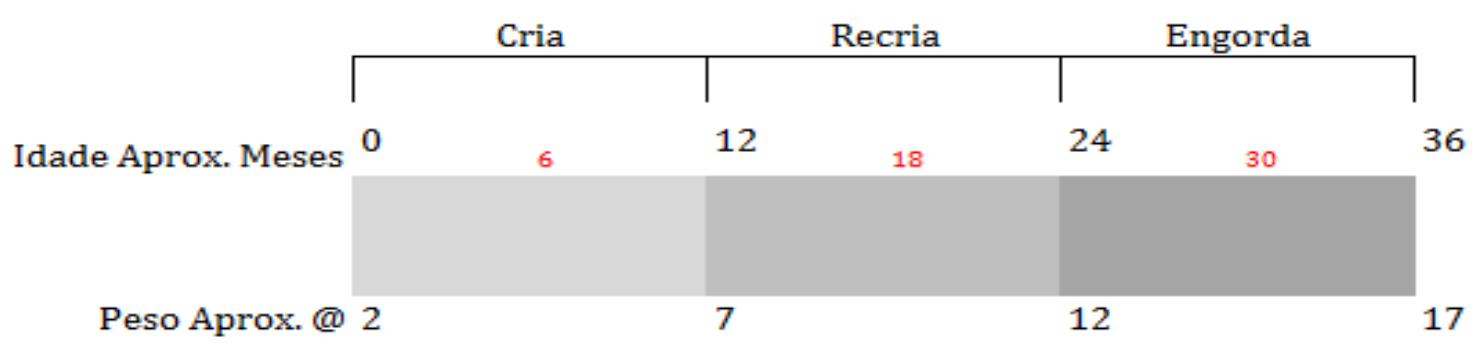

Fonte: Adaptado de Mendes, Zoccolotto e Nossa (2010).

A fase de cria inicia-se no nascimento e vai até o desmame (12 meses), que é quando o bezerro é separado da mãe (apartado), e não se alimentará mais do leite materno. Após o bezerro ser desmamado (de 12 a 24 meses), começa uma nova etapa de criação, denominada recria, onde o animal tem alimentação basicamente de pastagens e suplementação alimentar principalmente no período da seca, onde os pastos ficam prejudicados, assevera Mendes et al (2010). Nessa fase são identificados os animais com potencial de reprodução e os com potenciais para o abate.

Os animais destinados ao abate entram na terceira fase que é denominada engorda. Nessa fase é preparado com alimentação devida para o ganho de peso e em seguida 
destinado ao abate, onde normalmente é vendido a frigoríficos para que seja realizada mais uma etapa da cadeia produtiva da carne, enfatiza Mendes, Zoccolotto e Nossa (2010).

De acordo com Cervieri (2009) o segmento mais importante da vida do animal é o período do nascimento até a desmama (fase pré-puberdade), pois o bezerro consegue em sete meses atingir cerca de 25 a $50 \%$ de seu peso final de abate. Bovinos jovens apresentam melhor conversão alimentar, o que reflete positivamente na rentabilidade das operações que envolvem cria e recria de machos e fêmeas. Por isso, deve-se explorar a maior eficiência biológica apresentada por animais em idades mais jovens (até a puberdade).

$\mathrm{Na}$ fase da terminação, o animal deve atingir peso e acabamento de carcaça adequados, agregando valor a todo o trabalho desenvolvido na cria e recria. Do ponto de vista biológico, animais em terminação se encontram numa fase em que o crescimento já não é tão eficiente como na cria e recria. À medida que o animal se aproxima de seu peso maduro, a intensidade do crescimento, traduzida pelo ganho de peso, e a eficiência alimentar diminuem. A composição do ganho de peso passa a ser constituída em maior parte por tecido adiposo, o qual, em termos de energia consumida por quilo de tecido depositado, é menos eficiente que o tecido muscular (CERVIERI, 2009).

\subsubsection{Sistema de Produção para Bovinos de Corte}

Em conformidade com Euclides Filho (2000), existem basicamente três tipos de sistema de produção de carne bovina: extensivo, semi-intensivo e intensivo. O sistema de produção de gado de corte é o conjunto de tecnologias e práticas de manejo, bem como o tipo de animal, o propósito da criação, a raça e a ecorregião, na qual, a atividade é desenvolvida.

Sistema extensivo - as propriedades que trabalham com esse sistema de criação se caracterizam pelo uso, principalmente, dos recursos naturais que contém na região, as quais podem ser encontradas na, grande maioria, longe dos centros consumidores. Contudo, um dos principais problemas deste sistema é a falta de forragem que ocorre de forma periódica, conforme a época do ano, os animais são mestiços e a campo, não tendo 
nenhum tipo de suplemento alimentar, ocasionando a baixa produtividade (OLIVEIRA, et al, 2008).

Sistema semi-intensivo - é adotado por propriedades rurais especializadas, como empresas rurais, cuja localização pode ser próxima ou longe dos centros comerciais, tendo como base da alimentação as pastagens, porém, utiliza técnicas para a maior conservação da qualidade das forragens, além dessa, outra característica importante é a utilização dos suplementos minerais e concentrados. A suplementação alimentar concentrada pode ocorrer ao longo do ano, ou em alguns períodos, entretanto, a suplementação mineral acontece ao longo do ano, com o acompanhamento do controle zootécnico, profilático e reprodutivo. O emprego de métodos modernos de reprodução, como treinamento e capacitação dos funcionários é realizado conforme a necessidade do trabalho, além disso, o controle de enfermidades segue um padrão rigoroso. Nessas propriedades, existe a oferta de carne em toda época do ano (OLIVEIRA, et al, 2008).

Sistema intensivo - essas propriedades rurais se caracterizam pela criação em confinamento, é feito em piquetes com área restrita, oferecendo aos animais alimentação e água nos cochos para que o animal tenha o menor esforço possível para se alimentar, além disso, há um rigoroso controle na alimentação, que é constituída por suplementos, como a ração, o proteico e o sal. Existe também um rígido cuidado no controle das enfermidades, para isso, contam com funcionários capacitados. Esse sistema de criação ocorre no Brasil, na época das secas, quando as pastagens sofrem, o que acarreta a diminuição da oferta do gado, consequentemente, aumenta o valor da arroba do boi no mercado, e essas propriedades visam este mercado, já que, podem produzir a carne durante todo o ano (OLIVEIRA, et al, 2008).

\subsection{Custos De Produção e Contabilidade Rural}

Entende-se por custo de produção, explica Lopes e Carvalho (2006), a soma dos valores de todos os recursos (insumos) e operações (serviços) utilizados no processo produtivo de certa atividade (produção de gado de corte, especificamente neste caso).

Segundo Melz (2013) na contabilidade de custos é possível encontrar os conceitos que distinguem gastos de desembolsos, investimentos de custos e despesas, além do conceito de perdas normais e anormais. Para efeito de classificação, gasto pode ser 


\section{Revista

dividido em três modalidades: investimento, custo e despesa. Investimento é um gasto feito com a intenção de benefício por vários ciclos de operação.

Megliorini (2007) afirma ainda que o custo é conceituado como o gasto para aquisição e/ou produção de um bem ou serviço. Assim, entende-se por custo o gasto utilizado no momento da produção, independente de desembolso. Para ele, custo de produção na pecuária significa, portanto, o gasto com alimentação, sanidade, a exaustão da pastagem, a depreciação das instalações e equipamentos.

Apesar dos muitos problemas com relação ao processo de apuração de dados e da subjetividade na sua estimação, a determinação do custo de produção é uma prática necessária e indispensável ao bom administrador, constituindo-se em um valioso instrumento para as decisões do administrador, contador e seus usuários, esclarece Lopes e Carvalho (2006).

Pelo estudo sistemático dos custos incorridos na produção do gado de corte, pode o produtor fixar diretrizes e corrigir distorções, possibilitando a sobrevivência do sistema de produção de gado de corte em um mercado cada dia mais competitivo e exigente, reverbera Lopes e Carvalho (2006).

De acordo com Barbalho, Ferreira e Oliveira (2006) as principais aplicações e contribuições da contabilidade de custos na pecuária de corte são o conhecimento do custo efetivo dos gados; a definição do valor de estoque dos animais; constatação da rentabilidade após a venda; indicação do lucro e do estágio ideal para a venda; consideração da especialização mais rentável; analise de viabilidade mais rentável: arrendamento, sociedade ou empréstimo para aquisição de terras; redução de custos e despesas; realização de orçamentos e planejamentos a fim de reduzir dispêndio.

Para se chegar ao valor do custo operacional efetivo da pecuária devem-se somar ao valor da aquisição dos animais os gastos com alimentação, mão de obra, sanidade, reprodução, impostos e despesas diversas. O custo operacional total se dá com a adição dos gastos que não geram desembolso, neste caso, a depreciação. Para se chegar ao custo de produção total, é necessário, ainda, se adicionar as remunerações da terra, do capital investido, do capital de giro e do empresário ao custo operacional total, obtido a partir da soma dos custos descritos anteriormente ao valor de compra do rebanho (RAUPP; FUGANTI, 2014). 


\section{Contabilidade}

\subsubsection{Sistemas de Custeio}

Para Melz (2013) o objetivo de um sistema de custeio é acumular os custos e transferi-los para os produtos da forma mais adequada, representando um elemento essencial para a gestão da empresa. Dependendo das necessidades da empresa e de seu processo de produção ela optará pela melhor forma de acumular seus custos (MEGLIORINI, 2007).

Os mais conhecidos são o custeio por absorção e o custeio variável, chamados de custeios tradicionais. Na pecuária, como é o caso da economia, não existe grande distinção dos gastos e, portanto, a aplicação dos sistemas de custeio fica prejudicada, analisa Melz (2013).

Além da segregação entre custos operacionais e não operacionais, é possível a segregação entre custos fixos e variáveis. Segundo este critério, os custos fixos seriam a depreciação, a remuneração do empresário, a remuneração da terra, a remuneração do capital investido e os impostos, conforme Lopes e Carvalho (2006). Já os custos variáveis seriam a aquisição dos animais, a alimentação, a mão de obra, a sanidade, a reprodução, as despesas diversas e a remuneração do capital de giro.

Marion (2010) apresenta, ainda, duas possibilidades de se realizar o custeio da pecuária, através do custo histórico - limitado em termos gerenciais devido à defasagem dos valores - e através do valor de mercado - que atualiza os valores corrigindo a defasagem inerente ao outro método. Recomendando utilização de fórmula de cálculo de custos mista, que inclui o custo histórico corrigido, a equivalência patrimonial e o valor de mercado. Assim, este método permite a avaliação dos estoques a preços correntes, gerando ganhos informacionais ao gestor.

\subsubsection{Aplicação do Custeio na Pecuária}

O primeiro passo na apuração dos custos na pecuária de corte é a separação dos gastos em custos de produção e despesas da fazenda. Aquisição de animais, mão de obra que manipula o gado, sanidade, inseminação artificial, podem ser considerados custos diretos dos animais, pois são perfeitamente identificáveis por animal. A depreciação das instalações e equipamentos utilizados no manejo do gado é considerada custo indireto, 


\section{Revista

assim como a mão de obra que não tenha contato direto no manejo do gado (MELZ, 2013).

Para Lopes e Carvalho (2006) no custo total da produção são considerados os custos fixos - aqueles que não variam com a quantidade produzida, como depreciação, seguros, alguns impostos, remuneração do produtor rural ou do capital; e os custos variáveis, aqueles que variam de acordo com a quantidade produzida, e cuja duração é igual ou menor que o ciclo de produção, como a mão de obra, alimentação do rebanho, medicamentos, despesas gerais.

Se for utilizado o método do custo operacional de produção, como indica Lopes e Carvalho (2006), o que se refere ao custo de todos os recursos de produção que exigem desembolso por parte do produtor. Envolve o custo operacional efetivo e outros custos. Os custos operacionais efetivos são representados por mão de obra, alimentação, sanidade, reprodução, impostos, despesas diversas; e outros custos como sendo a depreciação e a mão de obra familiar.

De acordo com Marion (2010) os custos do rebanho podem ser divididos em custos de produção (diretos) ou gastos gerais da fazenda (indiretos).

Os impostos sobre a venda dos animais, energia, despesas diversas, seriam considerados despesas, na óptica contábil. A remuneração da terra, do capital investido e de giro, deve ser considerada parte do lucro que o empresário rural deseja obter. A remuneração sobre o capital é chamada de custo de oportunidade, ou, o montante de valor que se deixa de ganhar, ao optar por investir o capital em terras ao invés de outras atividades econômicas. Para conhecer e acompanhar os custos diretos envolvidos na produção torna-se necessária a confecção de alguns controles. Estes controles podem ser feitos de forma manual ou eletrônica, dependendo da disponibilidade de recursos do produtor, principalmente no que tange à infra-estrutura de energia, computador, internet e comunicação, qualificação da mão de obra seu comprometimento com o controle dos custos, designa MELZ, (2013).

\subsubsection{Tributação na Pecuária}

A comercialização de bovinos para o abate, em Mato Grosso, é tributada pelo Fundo Emergencial de Saúde Animal do Estado de Mato Grosso - (FESA); pelo Fundo Estadual de Transporte e Habitação - (FETHAB); e, pelo INDEA. 
O FESA é destinado para a defesa sanitária animal (FESA/MT, 2015); o FETHAB é destinado ao financiamento do planejamento, execução, acompanhamento e avaliação de obras e serviços de transportes e habitação em todo o território mato-grossense (SEFAZ/MT, 2015), o qual é repassado em parte para os municípios para a manutenção de estradas municipais. E a taxa do INDEA que assegura toda a estrutura que o órgão oferece aos produtores, como fiscalização e aplicação de vacinas, controle de zoonoses dos rebanhos em geral, etc. (INDEA, 2015).

Tabela 1 - Impostos incididos no ato da comercialização ao final do ano de 2015

\begin{tabular}{lcc}
\hline Impostos & Taxas \% & UPF/MT \\
\hline FESA/MT & 2,5 & 108,98 \\
FETHAB & 23,52 & 108,98 \\
INDEA & 0,04 & 108,98 \\
\hline
\end{tabular}

Fonte: Dados da pesquisa (2016).

\section{METODOLOGIA}

Em relação à abordagem, refere-se a um estudo quantitativo. Raupp e Bauren (2003) relatam que este tipo de abordagem se caracteriza pelo uso de instrumentos estatísticos, nos quais busca descrever significados que são considerados como indispensáveis aos objetos e atos do estudo.

O método de estudo desta pesquisa é descritivo. Gil (2002) relata que este tipo de pesquisa tem como objetivo principal, a descrição das informações coletadas em determinada população ou estabelecimento de relações entre as variáveis. Comprovando um conjunto de informações, através de pesquisas bibliográficas em livros e artigos científicos, e também em entrevistas com pessoas nas quais apresentam um grau de conhecimento relevante e experiência mais aprofundada sobre o determinado assunto em questão.

A pesquisa classifica-se como estudo de um caso, sendo realizada a análise dos fatos, a observação das informações a fim de obter um conhecimento do que foi estudado. Em se tratando dos instrumentos disponíveis na coleta de dados, foram utilizadas neste estudo a observação e a entrevista com os envolvidos no processo de bovinocultura da fazenda. Colauto e Beuren (2003) destacam que a observação tem como objetivo 
principal, proporcionar uma redução da subjetividade do processo de investigação, ou seja, essa vantagem está ligada ao fato em que o pesquisador se utiliza de seus próprios sentidos, relacionando-se diretamente com os fatos, questionados ao entrevistado.

A propriedade Fazenda Catarinense, onde é praticada a atividade de bovinocultura, está situada no sudoeste do Mato Grosso, na cidade de Denise, a 210km de Cuiabá. A Fazenda Catarinense conta com uma área territorial de aproximadamente 650 hectares, sendo 10 hectares destinados a reserva florestal, e 640 hectares em formações de pastagens. A fazenda possui uma estrutura especifica na qual auxilia todo o processo produtivo que está localizado na sede da fazenda.

Através da metodologia utilizada na coleta de informações, determinou-se o total de investimentos inseridos à Fazenda Catarinense em todo o processo produtivo. $\mathrm{O}$ instrumento de pesquisa foi aplicado no período de 04 e 12 de setembro de 2016, realizado com o proprietário da fazenda e três funcionários, onde aplicou-se uma entrevista semi estruturada, a qual permitiu uma maior liberdade e interatividade entre o pesquisador e o entrevistado.

O questionário aplicado na entrevista continha 20 questões, que nas quais tinham por objetivo de conhecer e coletar dados e informações sobre os custos gerados no processo produtivo da fazenda. Para tanto foi pesquisado as seguintes variáveis, como demonstra a tabela 2 .

Tabela 2 - Variáveis analisadas na Fazenda no ano de 2015.

\begin{tabular}{lc}
\hline Insumos & Equipamento \\
\hline Pastagens & Curral \\
Agulhas e Seringas & Caminhões \\
Vacinas & Tratores \\
Vermífugos & Adubadora \\
Energia Elétrica & Pulverizadores \\
Lubrificantes & Curral \\
Inseticidas & Caminhões \\
Adubos & \\
Sal Mineral & \\
Mão de Obra & \\
\hline
\end{tabular}

Fonte: Dados da pesquisa (2016).

Portanto foi tomado conhecimento de todas as características nas quais componham a estrutura física da Fazenda, como dimensão territorial, instalações, 
máquinas e equipamentos agrícolas, equipe de colaboradores, o número de cabeças de bovinos que a fazenda portava no final do no de 2015, e por final a lucratividade obtida ao final do ano de 2016.

Foi realizado duas etapas para o levantamento de informações da pesquisa. A primeira etapa foi realizada no dia 10/12/2016, onde colheu-se informações referentes ao inventario completo dos bens estruturais da fazenda, apurando o valor venal e vida útil de cada estrutura presente no objeto de pesquisa, sendo eles as instalações, dimensões estruturais, equipamentos agrícolas e composição do rebanho. A outra etapa realizada no dia 17/12/2016, ficou caracterizada pela aplicação do questionário, no qual obteve-se informações referentes a todo o processo produtivo. A partir disso, foi possível apurar pelas categorias e unidades, os custos, despesas, investimentos, e lucratividade do período, através do uso das tabelas do programa Excel.

\section{RESULTADOS}

\subsection{Caracterização da Fazenda Catarinense}

A tabela abaixo (tabela 3) demonstra os investimentos, quantidades e valor dos bens que a Fazenda Catarinense dispõe no ano de 2015.

Tabela 3- Características da Fazenda Catarinense em relação aos investimentos no ano de 2015.

\begin{tabular}{lccr}
\hline \multicolumn{1}{c}{ Investimento } & Quantidade (und) & \multicolumn{2}{c}{ Valor (R\$) } \\
\hline Área de Pastagem (HÁ) & 640 & $\mathrm{R} \$$ & $4.000 .000,00$ \\
Curral & 1 & $\mathrm{R} \$$ & $100.000,00$ \\
Caminhão & 1 & $\mathrm{R} \$$ & $120.000,00$ \\
Trator & 1 & $\mathrm{R} \$$ & $60.000,00$ \\
Aduba Dora & 1 & $\mathrm{R} \$$ & $40.000,00$ \\
Pulverizador & 1 & $\mathrm{R} \$$ & $50.000,00$ \\
\hline Total & & $\mathrm{R} \$$ & $4.370 .000,00$ \\
\hline Fonte: Dados da pesquisa (2016). & & &
\end{tabular}

\subsection{Quantidade do rebanho no início do período}

A Tabela 4 demonstra o número de cabeças de bovinos que a Fazenda Catarinense tinha no final do ano de 2015. 
Tabela 4- Quantidade de animas na fazenda no final de 2015.

Categorias

Bezerros 0/12 meses

Bezerras 0/12 meses

Novilhos 13/24 meses

Novilhas 13/2 4 meses

Matrizes

Touros para reprodução

Total
Quantidade (und) 75

Fonte: Dados da pesquisa (2016)

\subsection{Custos gerados no processo de engorda de bovinos em pastagens.}

O processo de engorda dos bovinos em pastagens ocorreu durante todo o ano de 2015. Posteriormente houve a comercialização de todos os animais da categoria Novilhos e Novilhas 25/36 para o frigorífico, com média de 16 arrobas ou 240 quilogramas por unidade.

Tabela 5 - Grupo de gastos gerados da fazenda no processo de bovinocultura no ano de 2016

\begin{tabular}{|c|c|c|c|c|}
\hline Grupos & Itens & \multicolumn{2}{|c|}{ Valores } & $\%$ \\
\hline \multirow{2}{*}{ Mão de Obra } & Mão de obra contratada & $\mathrm{R} \$$ & $39.600,00$ & \multirow{2}{*}{24,02} \\
\hline & Encargos Trabalhistas & $\mathrm{R} \$$ & $13.372,00$ & \\
\hline Alimentação & Sal mineral & $\mathrm{R} \$$ & $6.500,00$ & 2,95 \\
\hline \multirow{7}{*}{ Sanidade } & Agulhas e seringas & $\mathrm{R} \$$ & 140,00 & \multirow{7}{*}{1,43} \\
\hline & Vacina febre aftosa & $\mathrm{R} \$$ & 900,00 & \\
\hline & Vacina contra raiva & $\mathrm{R} \$$ & 550,00 & \\
\hline & Vacina contra carbúnculo & $\mathrm{R} \$$ & 400,00 & \\
\hline & Vermífugos & $\mathrm{R} \$$ & 700,00 & \\
\hline & Mata bicheiras & $\mathrm{R} \$$ & 230,00 & \\
\hline & Materiais Diversos & $\mathrm{R} \$$ & 225,00 & \\
\hline \multirow{6}{*}{ Despesas } & Energia & $\mathrm{R} \$$ & 550,00 & \multirow{6}{*}{3,46} \\
\hline & Combustível & $\mathrm{R} \$$ & $2.800,00$ & \\
\hline & Lubrificantes & $\mathrm{R} \$$ & 100,00 & \\
\hline & Reparo de benfeitorias & $\mathrm{R} \$$ & $1.700,00$ & \\
\hline & Reparo de máquinas e equipamentos & $\mathrm{R} \$$ & $2.000,00$ & \\
\hline & Equipamento de proteção individual & $\mathrm{R} \$$ & 500,00 & \\
\hline Depreciação & Depreciação de Instalações & $\mathrm{R} \$$ & $5.000,00$ & 22,68 \\
\hline
\end{tabular}




\begin{tabular}{clrrr} 
& Depreciação de Veículos & $\mathrm{R} \$$ & $36.000,00$ & \\
& Depreciação de máquinas e equipamentos & $\mathrm{R} \$$ & $9.000,00$ & \\
\hline \multirow{3}{*}{ Pastagens } & Calcário & $\mathrm{R} \$$ & $10.000,00$ & \\
& Adubo orgânico & $\mathrm{R} \$$ & $1.250,00$ & \multirow{2}{*}{29,59} \\
& Inseticida & $\mathrm{R} \$$ & $48.000,00$ & \\
& Sementes & $\mathrm{R} \$$ & $6.000,00$ & \\
\hline Exaustão & Exaustão de pastagens & $\mathrm{R} \$$ & $35.000,00$ & 15,87 \\
\hline Total & & $\mathrm{R} \$ 220.517,00$ & 100 \\
\hline
\end{tabular}

Fonte: Dados da pesquisa (2016).

Na Tabela 5 observa-se o grupo de gastos gerados no ano de 2016 com o processo de engorda. A composição dos grupos segue a proposta de Lopes e Carvalho (2002), no qual identifica que neste caso são os novilhos e novilhas de 13/24 e 25/36, deixando de contabilizar o grupo de reprodução que são os touros, as matrizes e os bezerros de 0 / 12 , pois não há custos neste grupo.

Através da tabela 5, constatou-se que o valor total anual gasto com mão-de-obra da fazenda foi de $R$ \$ 52.972,00 sendo $R$ \$ 39.600,00 em salários e $R$ \$13.272,00 em encargos sociais e trabalhistas - férias, décimo terceiro salário, descanso semanal remunerado, INSS. A composição desses valores foi possível através do levantamento da folha de pagamento dos três funcionários da fazenda.

Em relação à alimentação, os animais recebem, além do capim em pastagens, uma suplementação orgânica específica para o seu desenvolvimento, neste caso o sal mineral, onde incorreu um gasto no valor de R \$ 6.500,00 no ano de 2016.

Nos custos gerados com sanidade, as agulhas e seringas, os mata bicheiras e os materiais diversos tiveram os valores fixados no ano de 2016 em R\$ 140,00; R\$ 230,00 e R \$225,00 respectivamente, e foram adquiridos conforme a necessidade. Já as vacinas para a prevenção de doenças tiveram um gasto de R \$2.550,00 no ano de 2016.

A fazenda teve gastos de energia no ano de 2016 no valor de $\mathrm{R} \$ 550,00$. A despesa com combustíveis e lubrificantes foi de $\mathrm{R} \$ 2.800,00$ e $\mathrm{R} \$ 100,00$, respectivamente, gastos estes referentes ao uso dos maquinários envolvidos no processo, e ainda, gastos com reparo de maquinas e equipamentos no valor de $\mathrm{R} \$ 2.000,00$. Os reparos de benfeitoria construção de piquetes, currais e cercas - foram no valor de $\mathrm{R} \$ 1.700,00$. Equipamentos de proteção individual ficaram com despesas no valor de $\mathrm{R} \$ 500,00$. E aquelas que não 
geram desembolso, tem-se a depreciação de instalações, veículos, maquinas e equipamentos, que foram mensurados em $R \$ 55.000,00$; e, a exaustão foi de $R \$$ $35.000,00$.

A pastagem apresenta custos com sementes e insumos utilizados na manutenção do capim. Para o manejo adequado do gado bovino, utiliza-se a proporção de 1 a 1/12 hectare de pasto para cada animal. O custo com sementes é computado apenas em locais onde a pastagem já não tem possibilidade de desenvolvimento, assim é necessário o plantio de novas sementes. Em cerca de 70 hectares da propriedade foi refeito o plantio de sementes no ano de 2016, com gasto de $\mathrm{R} \$ 6.000,00$. Os 430 hectares restantes tiveram apenas que receber certa quantia de novos insumos, como por exemplo, calcário, em torno de 420.000 quilos, no valor de $\mathrm{R} \$ 10.000,00$; adubo orgânico, 70.000 quilos, a um custo de $\mathrm{R} \$ 1.250,00$. E por fim, os inseticidas que foram usados aproximadamente 500litros, no valor de $\mathrm{R} \$ 48.000,00$.

Ainda com os resultados da tabela, foi possível a mensurados custos em fixos e variáveis, permitindo inclusive, que se apurasse o custo unitário, ou seja, o custo por cabeça, considerando os animais que estão na etapa de engorda, e prontos para a comercialização. O processo de engorda compreende os animais em idade de 25 a 36 meses, novilhos e novilhas, que foram totalizados em 176 cabeças. A Tabela 6 a seguir demonstra a separação entre custos.

Tabela 6 - Representação dos custos fixos e variáveis da fazenda catarinense no ano 2015.

\begin{tabular}{clrc}
\hline Tipo Custo & \multicolumn{1}{c}{ Descrição } & \multicolumn{1}{c}{ Valor } & \% \\
\hline \multirow{2}{*}{ Custos Fixos } & Exaustão de Pastagens & $35.000,00$ & $15,87 \%$ \\
& Depreciação Instalações & $5.000,00$ & $2,27 \%$ \\
& Depreciação Veículos & $36.000,00$ & $16,32 \%$ \\
& Depreciação Máquinas & $9.000,00$ & $4,09 \%$ \\
\hline Total & & $\mathbf{8 5 . 0 0 0 , 0 0}$ & $\mathbf{3 8 , 5 5 \%}$ \\
& Mão de Obra & $39.600,00$ & $17,95 \%$ \\
& Materiais diversos & 225,00 & $0,10 \%$ \\
& Encargos trabalhistas & $13.372,00$ & $6,06 \%$ \\
& Sal Mineral & $6.500,00$ & $2,95 \%$ \\
& Agulhas e seringas & 140,00 & $0,06 \%$ \\
& Vacina febre aftosa & 900,00 & $0,41 \%$
\end{tabular}




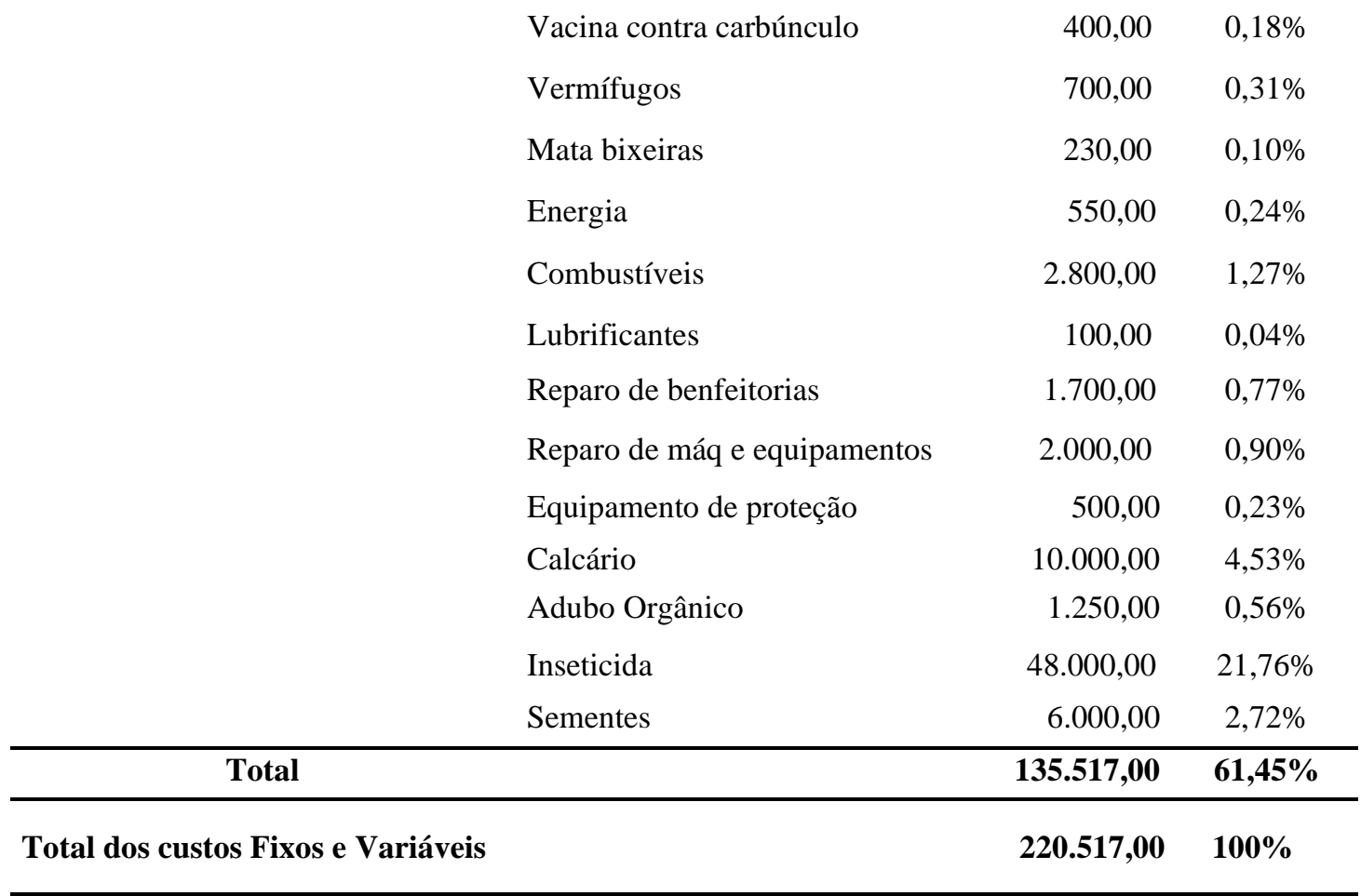

Fonte: Dados da pesquisa (2016).

Segundo a metodologia adotada, o total dos custos fixos, é o resultado da soma das depreciações e da exaustão, enquanto, os demais gastos são classificados como custos variáveis. Dessa forma, o custo fixo foi $\mathrm{R} \$ 85.000,00$, e o custo variável foi $\mathrm{R} \$ 135.517,00$. Somando-se todos os custos obtêm-se o valor total de $\mathrm{R} \$ 220.517,00$. Considerando os 176animais que absorvem este custo, apurou-se um custo unitário de $\mathrm{R} \$ 1.252,93$.

\subsection{Apuração da receita}

A tabela abaixo demonstra como foi auferida a receita proveniente da comercialização dos novilhos e novilhas de 25/36 meses.

Tabela 8- Demonstração da receita de venda.

\begin{tabular}{ccccc}
\hline Categorias & Quantidade & Arrobas & Valor & $\begin{array}{c}\text { Valor da receita } \\
\text { auferida }\end{array}$ \\
\hline Novilhas 25/36 & 80 & 16 & 120 & $153.600,00$ \\
Novilhos 25/36 & 96 & 16 & 120 & $184.320,00$ \\
TOTAL & & & & $\mathbf{3 3 7 . 9 2 0 , 0 0}$ \\
\hline
\end{tabular}

Fonte: Dados da pesquisa (2016).

Ao final do período, a fazenda comercializou todo seu estoque de novilhas e novilhos 25/36 meses, ou seja, 176 cabeças. A venda dos 176 animais com peso médio 


\section{Contabilidade}

de 16 arrobas cada totalizou 2.816 arrobas de bovinos vendidas. De tal modo, multiplicouse a quantidade total de arrobas pelo preço: 2.816 x $\mathrm{R} \$ 120,00$, totalizando uma receita de vendas de $\mathrm{R} \$ 337.920,00$.

\subsection{Apuração dos impostos}

A tabela 9 abaixo demonstra os impostos incidentes sobre a comercialização dos bovinos no ano de 2015 .

Tabela 9-Demonstração do cálculo dos impostos incidentes sobre a comercialização

\begin{tabular}{clllllr}
\hline Categorias & Impostos & Taxas \% & UPF/MT & Quantidades & Valores \\
\hline \multirow{2}{*}{ Novilhas 25/36 } & FESA MT & $2,50 \%$ & 108,98 & 80 & $\mathrm{R} \$$ & 217,96 \\
& FETHAB & $23,52 \%$ & 108,98 & 80 & $\mathrm{R} \$$ & $2.050,56$ \\
& INDEA & $0,04 \%$ & 108,98 & 80 & $\mathrm{R} \$$ & 3,48 \\
& & & & Total & $\mathbf{R} \mathbf{2 . 2 7 2 , 0 0}$ \\
Novilhos 25/36\% & FESA MT & $2,50 \%$ & 108,98 & 96 & $\mathrm{R} \$$ & 261,55 \\
& INDEA & $0,04 \%$ & 108,98 & 96 & $\mathrm{R} \$$ & $2.460,68$ \\
& & & & Total & R \$ & 4,18 \\
& & & & & $\mathbf{R} \mathbf{2 . 7 2 6 , 4 1}$ \\
\hline
\end{tabular}

Fonte: Dados da pesquisa (2016).

\subsection{Apuração do resultado do exercício}

A tabela 10 demonstra como foi encontrado o Lucro líquido (antes das provisões do IR e CSLL):

Tabela 10 - Demonstração da apuração do resultado do exercício

\begin{tabular}{ccr}
\hline Receita Bruta de Venda de Novilhas 25/36 & $\mathrm{R} \$$ & $153.600,00$ \\
(-) Custo Produto Vendido & $-\mathrm{R} \$$ & $100.234,40$ \\
Receita Bruta Venda de Novilhos 25/36 & $\mathrm{R} \$$ & $184.320,00$ \\
(-) Custo Produto Vendido & $-\mathrm{R} \$$ & $120.281,28$ \\
(=) Lucro Bruto & $\mathbf{R} \$$ & $\mathbf{1 1 7 . 4 0 4 , 3 2}$ \\
(-) Despesas Administrativas & $-\mathrm{R} \$$ & $4.998,42$ \\
Imposto sobre venda novilhas (25/36) & $\mathrm{R} \$$ & $2.272,00$ \\
Imposto sobre venda novilhos (25/36) & $\mathrm{R} \$$ & $2.726,41$ \\
(=) Lucro Líquido antes do IR e CSLL & $\mathbf{R} \$$ & $\mathbf{1 1 2 . 4 0 5 , 9 0}$ \\
\hline
\end{tabular}

Fonte: Dados da pesquisa (2016). 


\section{Revista

Sabendo-se que a Receita Bruta foi de $\mathrm{R} \$ 337.920,00$, os custos no processo de produção foram de $\mathrm{R} \$ 220.517,00$, e os custos com tributação no ato da comercialização foram de $\mathrm{R} \$ 4.998,42$, obteve-se então um Lucro Líquido de $\mathrm{R} \$ 112.404,58$.

Raupp e Fuganti (2014) realizaram um estudo sobre o gerenciamento de custos na pecuária de corte em duas fazendas distintas situadas no município de Primavera do Leste, no Estado do Mato Grosso no ano de 2014. O estudo se teve por meio de um comparativo, entre a engorda de bovinos em pastagens realizada na fazenda A, e o cultivo dos mesmos, através de confinamento realizado na fazenda B, com um lote de 100 bovinos em cada fazenda. Levando em consideração os resultados alcançados na fazenda A, observou-se que os autores obtiveram números parecidos com o presente estudo, como demonstra a Tabela 11.

Tabela 11 -Comparação dos custos e receitas auferidas no ano de 2015

\begin{tabular}{llr}
\multicolumn{1}{c}{ Variáveis/ano } & \multicolumn{1}{c}{ Ano 2015 } \\
\hline Custo em média por arroba @ & $\mathrm{R} \$$ & 78,31 \\
Custo unitário & $\mathrm{R} \$$ & $1.252,93$ \\
Custo Total & $\mathrm{R} \$$ & $220.515,68$ \\
Despesas Unitárias & $\mathrm{R} \$$ & 28,40 \\
Despesas Totais & $\mathrm{R} \$$ & $4.998,41$ \\
Receita Unitária & $\mathrm{R} \$$ & $1.920,00$ \\
Receita Total & $\mathrm{R} \$$ & $337.920,00$ \\
Lucro por arroba @ & $\mathrm{R} \$$ & 39,92 \\
Lucro Unitário & $\mathrm{R} \$$ & 638,67 \\
Lucro Total & $\mathrm{R} \$$ & $112.405,90$ \\
$\%$ Lucro sobre receita & $\mathrm{R} \$$ & 33,26 \\
\hline
\end{tabular}

Fonte: Dados da pesquisa (2016).

Enquanto o custo unitário do presente estudo foi de R \$1.252,93, Raupp e Fuganti (2014), auferiram um custo unitário de $\mathrm{R} \$ 1.420,71$. Houve uma pequena diferença no comparativo de percentuais na divisão dos custos fixos e variáveis, já que na pesquisa dos autores os custos fixos representaram 35,03\% e as variáveis $64,97 \%$ do valor do custo unitário, enquanto a presente pesquisa apresentou 38,54\% e 61,46\% respectivamente

\section{CONSIDERAÇÕES FINAIS}

O objetivo proposto da pesquisa foi determinar comparativamente os custos de produção e a lucratividade para a atividade de produção de bovinos de corte na 
Fazenda Catarinense no ano de 2015, e os mesmo foram alcançados através do levantamento de dados através da metodologia de estudo de um caso.

O processo de engorda compreende os animais em idade de 25 a 36 meses, (novilhos e novilhas) idade essa em que o animal está apto para ser comercializado pois no final dessa fase ele já está com 16 arrobas ou $240 \mathrm{~kg}$. No final de 2016 foram totalizados 176 cabeças. Como a propriedade faz a atividade de cria-recria-engorda, os animais não possuem custo de aquisição, fazendo com que os resultados apurados no estudo, provassem que é lucrativa a criação de gado no sistema extensivo realizado pela fazenda em estudo, localizada no município de Denise - MT.

Os resultados gerados pela criação dos animais foram bem aceitos pelo pecuarista, e confirmou-se que os custos com maior relevância para a produção de carne são os com as Pastagens que representam $\mathrm{R} \$ 65.250,00$ ou 29,59\% dos custos totais. E o menor custo, porém não menos importante que os custos com sanidade do animal (vacinas/medicamentos) que representaram um desembolso de $\mathrm{R} \$ 3.145,00$ ou 1,43\% dos totais dos custos.

Para a apuração do resultado do exercício e a determinação do lucro utilizou-se para receita bruta, quantidade produzida x preço de venda na região, e desse resultado diminuiu-se os custos levantados da respectiva atividade.

E como sugestões para trabalhos futuros é possível analisar os anos posteriores para comparar os comportamentos dos custos de produção e preço de comercialização identificando assim possíveis gargalos e por seguinte maximizar o resultado para o produtor rural, e também desenvolver a pesquisa em outras regiões no Mato Grosso para verificar se há disparidades entre regiões.

\begin{abstract}
The present work had the objective of analyzing the management of the costs incurred in the system of production of cattle grazing at Fazenda Catarinense in the municipality of Denise - MT, evidencing the productive chain of production, during the fattening stage in the year 2015. The methodology used for the study was descriptive in nature, with a qualitative-quantitative approach, using as a technical procedure the study of a case. The results obtained in the research showed the variation of costs and expenses generated by the production of beef cattle in pastures, and their profitability at the end of the period. It was evidenced through the research that cattle raising for slaughter at Fazenda Catarinense is profitable, providing a profit of approximately $50 \%$ of the costs incurred in the stage of fattening.
\end{abstract}


Keywords: Cattle Culture. Costs. Production.

\section{BIBLIOGRAFIA}

ASSOCIAÇÃO BRASILEIRA DAS INDÚSTRIAS EXPORTADORAS DE CARNE(ABIEC). Estatísticas de exportação de carne. São Paulo: ABEIC, 2013. Disponível em:

<http://www.abiec.com.br/download/Relatorio\%20exportacao\%202013_jan_dez.pdf> Acesso em: 17 Dez 2016.

BARCELLOS, J. O.J. et al. A bovinocultura de corte frente a agriculturização no sul do 176d176P176l, 2005, p.01.

BONJOUR, Sandra Cristina M.; FIGUEIREDO, Adriano Marcos R.; MARTA, José Manuel C. A Pecuária de Corte no Estado de Mato Grosso. XLVI Congresso da Sociedade Brasileira de Economia, Administração e Sociologia Rural, Rio Branco-AC. Cuiabá: UFMT, 2008. Disponível em: 〈http://www.sober.org.br/palestra/9/519.pdf>. Acesso em: 14 Dez 2016.

CERVIERI, Rafael da Costa. Produção de Gado de Corte: conceitos técnicos e econômicos. São Paulo: BeefPoint, 2009. Disponível em: $<$ http://www.beefpoint.com.br/sobre-o-site/novas-do-site/producao-de-gado-de-corteconceitos-tecnicos-e-economicos-57829/> Acesso em: 14 Dez 2016.

COLAUTO, Romualdo Douglas; BEUREN, Ilse Maria. Coleta, análise e interpretação dos dados. In. BEUREN, Ilse Maria. (Org). Como elaborar trabalhos monográficos em contabilidade. 3.ed. São Paulo: Atlas, 2006.

CONFEDERAÇÃO NACIONAL DE ABASTECIMENTO- CNA. Substituição da pecuária extensiva. Disponível em: <//www.pecuaria.com.br/info.php?ver=3877>. Acesso em20/04/2015.

CNA. O Setor de Agronegócio no Brasil. Brasília, 2006. Disponível em: <http://investimentos.mdic.gov.br/public/arquivo/arq1273158100.pdf> Acesso em: 13 Dez 2016.

Balanço 2015 Perspectivas 2016. Brasília, 2015. Disponível em: <http://www.canaldoprodutor.com.br/sites/default/files/01\%20Balanco2015\%20Perspec tivas2016_panorama_economico_0.pdf>. Acesso em: 13 Dez 2016.

CONTINI, Elisio; GASQUES, José Garcia; LEONARDI, Renato Barros de Aguiar; BASTOS, Eliana Teles. Evolução Recente e Tendências do Agronegócio. Revista de Política Agrícola, Ano XV $-\mathrm{N}^{\mathrm{o}} 1-$ Jan./Fev./Mar. 2006. Disponível em: $<$ http://ainfo.cnptia.embrapa.br/digital/bitstream/item/62803/1/Evolucao-recente-etendencias-do-agronegocio.pdf> Acesso em: 13 Dez 2016. 
EUCLIDES FILHO, K. Produção de bovinos de corte e o trinômio genótipo ambiente -mercado. Embrapa Gado de Corte. Campo Grande, 2000.

FILHO, Amado de Oliveira; GIORDANO, Samuel; MACIEL, Wilton Rogério S. Diretrizes para o Desenvolvimento da Pecuária de Corte no Mato Grosso: Visão de universitários e pecuaristas. Mato Grosso: ACRIMAT, 2012. Disponível em: $<$ http://acrimat.com.br/portal/wp-content/uploads/2016/01/Diretrizes-para-odesenvolvimento-da-pecu\%C3\%A1ria-de-corte-de-Mato-Grosso.pdf> Acesso em: 14 Dez 2016.

GIL, A. C. Como elaborar projetos de pesquisa. 4. 177d. São Paulo: Atlas, 2002.

HOFFMANN, Alvair; MORAES, Eduardo Henrique B. Q. de; MOUSQUER, Claudio Jonasson; et al. Produção de Bovinos de Corte no Sistema de Pasto-suplemento no Período da Seca. Nativa, v. 02, n. 02, p. 119-130, abr./jun. 2014. Sinop, 2014. Disponível em:

<www.periodicoscientificos.ufmt.br/ojs/index.php/nativa/article/download/1298/pdf.>

Acesso em: 14 Dez 2016.

INSTITUTO BRASILEIRO DE GEOGRAFIA E ESTATÍSTICA (IBGE). Anuário Estatístico do Brasil,2011.

INSTITUTO DE DEFESA AGROPECUÁRIO DO ESTADO DO MATO GROSSO INDEA, 2015.

LOPES, Marco Aurélio; CARVAlHO, Francisval de Melo. Custo de Produção do Gado de Corte. Lavras: UFLA, 2006. Disponível em: <http://livraria.editora.ufla.br/upload/boletim/tecnico/boletim-tecnico-47.pdf.> Acesso em: 15 Dez 2016.

MARION, J. C. Contabilidade Rural: contabilidade agrícola, contabilidade da pecuária - imposto de renda pessoa jurídica. São Paulo: Atlas, 2010.

MEGLIORINI, E. Custos: análise e gestão. 2. ed. São Paulo: Pearson Prentice Hall, 2007.

MELZ, Laércio Juarez. Custos de produção de gado bovino: revisão sob o enfoque da contabilidade de custos. 2013.2 Disponível em: <http://www.custoseagronegocioonline.com.br/numero1v9/Bovino.pdf > Acesso em: 13 Dez 2016.

MENDES, Alcindo C. Argolo; ZOCCOLOTTO, Robson; NOSSA, Valcemiro. Um Modelo de Simulação como Ferramenta de Planejamento na Bovinocultura de Corte. São Paulo: FUCAPE, 2010. Disponível em: <http://www.fucape.br/_public/producao_cientifica/2/Mendes\%20-

\%20um\%20modelo\%20de\%20simulacao.pdf.> Acesso em: 13 Dez 2016. 
OLIVEIRA, R. L.; BARBOSA, M. A. A. F; BALGADO, A. R.; RIBEIRO, M. D. O zootecnista e os sistemas de produção de bovinos de corte. Universidade Federal da Paraíba. João Pessoa (PB), 2008.

Portal Do Ministério De Agricultura, Pecuária E Abastecimento - MAPA. Bovinos e bubalinos. 2015.2 Disponível em: <http://www.agricultura.gov.br/animal/especies/bovinos-e-bubalinos >- Acesso em22/04/2015.

RAUPP, Fabiano Maury; FUGANTI, Eduardo Nery. Gerenciamento de Custos na Pecuária de Corte: um comparativo entre a engorda em pastagem e em confinamento. XVII SIMPOI. São Paulo: FGV-EAESP, 2014. Disponível em: <http://www.simpoi.fgvsp.br/arquivo/2014/artigos/E2014_T00082_PCN74450.pdf.> Acesso em: 15 Dez 2016.

VALLE, Ezequiel Rodrigues do. Boas Práticas Agropecuárias - bovinos de corte. $-1^{\text {a }}$ Ed. 2a Impr. Campo Grande: Embrapa Gado de Corte, 2007. Disponível em: <http://www.agricultura.gov.br/arq_editor/7.pdf.> Acesso em: 14 Dez 2016.

\section{APÊNDICE}

Questionário para entrevista

1. Qual a localidade especifica da Fazenda?

2. Qual o tamanho da área estrutural da Fazenda Catarinense?

3. Quais são os integrantes do quadro de colaboradores envolvidos no projeto?

4. Quais as medidas estruturais que a Fazenda disponibiliza para o desenvolvimento do projeto?

5. Quais são os implementos agrícolas, e seu valor venal, que a Fazenda possui?

6. Qual a raça de bovinos cultivada na Fazenda?

7. Qual é o número de cabeças de bovinos que a Fazenda possuiu no ano de 2015 , e possui no ano de $2016 ?$

8. Quais as categorias de bovinos que a Fazenda possui?

9. Quais os bovinos específicos destinados á reprodução?

10. Quais os bovinos específicos destinados á engorda e comercialização?

11. Qual é a principal fonte de alimentação dos bovinos?

12. Quais os produtos e seus respectivos custos utilizados na manutenção do rebanho no ano de 2015? 
13. Quais os produtos e seus respectivos custos utilizados na manutenção da pastagem no ano de 2015 ?

14. Qual o tempo estimado para um boi estar pronto para a comercialização?

15. Qual a média de bovinos nascidos e comercializados anualmente?

16. Em relação à reprodução e multiplicação do rebanho, como é realizado o processo?

17. Em relação à cria e o desenvolvimento desses animais, como é realizado o processo?

18. Quais foram os bovinos comercializados no ano de 2015 ?

19. Qual foi peso médio de um boi no ato de sua comercialização no ano de 2015 ?

20. Qual o valor por arroba, dos bovinos comercializados no ano de 2015? 